\title{
Potential Health Implications of Medication Therapy Management Eligibility Criteria in the Patient Protection and Affordable Care Act Across Racial and Ethnic Groups
}

\author{
Junling Wang, PhD; Yanru Qiao, MS; Ya-Chen Tina Shih, PhD; JoEllen Jarrett-Jamison, BS; \\ Christina A. Spivey, PhD; Jim Y. Wan, PhD; Shelley I. White-Means, PhD; \\ Samuel Dagogo-Jack, MD, FRCP; William C. Cushman, MD; and \\ Marie Chisholm-Burns, PharmD, MPH, MBA, FCCP, FASHP
}

\section{ABSTRACT}

BACKGROUND: The Medicare Prescription Drug, Improvement, and Modernization Act requires Part D plans to establish programs to provide medication therapy management (MTM) services starting from 2006. MTM services have been found to improve patient outcomes from pharmacotherapy, reduce emergency room visits and hospitalizations, and reduce health care costs in a cost-effective fashion. However, previous research found that non-Hispanic blacks (blacks) and Hispanics may be less likely to be eligible for MTM services than non-Hispanic whites (whites) among the Medicare population, according to current Medicare MTM eligibility criteria. This finding is because Medicare MTM eligibility criteria are predominantly based on medication use and costs, and blacks and Hispanics tend to use fewer prescription medications and incur lower prescription medication costs. The Patient Protection and Affordable Care Act (PPACA) laid out a set of MTM eligibility criteria for eligible entities to target patients for MTM services: "(1) take 4 or more prescribed medications ...; (2) take any 'high risk' medications; (3) have 2 or more chronic diseases ... or (4) have undergone a transition of care, or other factors ... that are likely to create a high risk of medication-related problems."

OBJECTIVES: To (a) examine racial/ethnic disparities in meeting the eligibility criteria for MTM services in PPACA among the Medicare population and (b) determine whether there would be greater disparities in health and economic outcomes among MTM-ineligible than MTM-eligible groups.

METHODS: This was a retrospective cross-sectional analysis of the Medicare Current Beneficiaries Survey (2007-2008). To determine medication characteristics, the U.S. Food and Drug Administration's Electronic Orange Book was also used. Proportions of the population eligible for MTM services based on PPACA MTM eligibility criteria were compared across racial and ethnic groups using a chi-square test; a logistic regression model was used to adjust for population sociodemographic and health characteristics. Health and economic outcomes examined included health status (self-perceived good health status, number of chronic diseases, activities of daily living [ADLs], and instrumental activities of daily living [IADLs]), health services utilization and costs (physician visits, emergency room visits, and total health care costs), and medication use patterns (generic dispensing ratio). To determine difference in disparities across MTM eligibility categories, difference-in-differences regressions of various functional forms were employed, depending on the nature of the dependent variables. Interaction terms between the dummy variables for minority groups (e.g., blacks or Hispanics) and MTM eligibility were included to test whether disparity patterns varied between MTM-ineligible and MTMeligible individuals.
RESULTS: The sample consisted of 12,966 Medicare beneficiaries, of which 11,161 were white, 930 were black, and 875 were Hispanic. of the study sample, 9,992 whites $(86.4 \%), 825$ blacks $(86.3 \%)$, and 733 Hispanics (80.6\%) were eligible for MTM. The difference between whites and Hispanics was significant $(P<0.050)$, and the difference between whites and blacks was not significant $(P>0.050)$. In multivariate analyses, significant disparity in eligibility for MTM services was found only between Hispanics and whites (odds ratio $[0 \mathrm{R}]=0.59 ; 95 \% \mathrm{Cl}=0.43-0.82$ ) but not between blacks and whites $(0 \mathrm{R}=0.78 ; 95 \% \mathrm{Cl}=0.55-1.09)$. Disparities were greater among the MTM-ineligible than the MTM-eligible populations in self-perceived health status, ADLs, and IADLs for both blacks and Hispanics compared with whites. When analyzing the number of chronic conditions, the number and costs of physician visits, and total health care costs, the authors of this study found lower racial and ethnic disparities among the ineligible population than the eligible population.

CONCLUSIONS: Hispanics are significantly less likely than whites to qualify for MTM among the Medicare population, according to MTM eligibility criteria stipulated in the PPACA. PPACA MTM eligibility criteria may aggravate existing racial and ethnic disparities in health status but may remediate racial and ethnic disparities in health services utilization. Alternative MTM eligibility criteria other than PPACA MTM eligibility criteria may be needed to improve the efficiency and equity of access to Medicare Part D MTM programs.

J Manag Care Spec Pharm. 2015;21(11):993-1003

Copyright $\odot 2015$, Academy of Managed Care Pharmacy. All rights reserved.

\section{What is already known about this subject}

Since 2006, the Medicare Prescription Drug, Improvement, and Modernization Act requires Part D plans to establish programs to provide medication therapy management (MTM) services.

Previous studies found that blacks and Hispanics may be less likely to be eligible for MTM services than whites among the Medicare population, according to current Medicare MTM eligibility criteria.

The Patient Protection and Affordable Care Act (PPACA) laid out a set of MTM eligibility criteria for eligible entities to target patients for MTM services with grants or contracts from the Centers for Medicare \& Medicaid Services, although the time line for the implementation of these provisions has not been determined. 


\section{What this study adds}

Disparities were greater among the MTM-ineligible than the MTM-eligible populations in self-perceived health status, activities of daily living, and instrumental activities of daily living for blacks and Hispanics compared with whites.

When analyzing the number of chronic conditions, the number and costs of physician visits, and total health care costs, this study found lower racial and ethnic disparities among the ineligible population than the eligible population.

PPACA MTM eligibility criteria may aggravate existing racial and ethnic disparities in health status but may remediate racial and ethnic disparities in health services utilization.

$\mathrm{D}$ rug-related morbidity and mortality in the ambulatory setting results in significant social burden. ${ }^{1}$ These outcomes are especially daunting among the elderly, owing to age-related changes in pharmacokinetics and pharmacodynamics, elevated sensitivity to drug effects, and increased use of medications. ${ }^{2}$ Therefore, the Medicare Prescription Drug, Improvement, and Modernization Act (MMA) requires Part D plans to establish programs to provide medication therapy management (MTM) services starting from 2006, aiming to "optimize therapeutic outcomes through improved medication use and to reduce the risk of adverse events." ${ }^{3}$

MTM services are particularly beneficial for patients with chronic diseases (e.g., diabetes and hypertension) for whom the management of pharmacotherapy plays a major role..$^{4-7}$ MTM services have been found to improve patients' outcomes from pharmacotherapy, reduce emergency room visits and hospitalizations, and reduce health care costs in a cost-effective fashion. ${ }^{4-7}$

According to the MMA, Part D plans are only required to target patients (a) with multiple chronic conditions, (b) who also use multiple Part D drugs, and (c) who incur drug costs exceeding a certain drug cost threshold. ${ }^{3}$ Wang et al. has found that under the MTM eligibility criteria set forth in the MMA, non-Hispanic blacks (blacks) and Hispanics may be less likely to be eligible for MTM services than non-Hispanic whites (whites) among the Medicare population, according to current Medicare MTM eligibility criteria. ${ }^{8,9}$ This disparity is because Medicare MTM eligibility criteria are predominantly based on medication use and costs, and blacks and Hispanics tend to use fewer prescription medications and incur lower prescription medication costs. ${ }^{3,10,11}$ Further, Wang et al. found that existing Medicare MTM eligibility criteria may aggravate, rather than remediate, racial and ethnic disparities in health status. ${ }^{12}$

The Patient Protection and Affordable Care Act (PPACA) laid out a set of MTM eligibility criteria for eligible entities to target patients for MTM services: "(1) take 4 or more prescribed medications (including over-the-counter medications and dietary supplements); (2) take any 'high risk' medications; (3) have 2 or more chronic diseases ... or (4) have undergone a transition of care, or other factors... that are likely to create a high risk of medication-related problems." 13 These criteria are less restrictive than the MTM eligibility criteria under the MMA mainly because patients do not need to meet all eligibility criteria, while MMA MTM eligibility criteria require patients to meet all eligibility criteria. The timeline for the implementation of these provisions has not been determined.

The objective of this study was to examine (a) racial and ethnic disparities in meeting these MTM eligibility criteria as stipulated in the PPACA among the Medicare population; and (b) possible greater disparities in health and economic outcomes among MTM-ineligible than MTM-eligible groups according to PPACA MTM eligibility criteria. The overarching hypothesis is that there would be greater disparities in health and economic outcomes among the MTM-ineligible group than among the MTM-eligible group, which suggests that disparity issues among the Medicare population may not be addressed effectively using PPACA MTM eligibility criteria; the MTM eligibility criteria in PPACA may potentially perpetuate the existing racial and ethnic disparities in health and economic outcomes.

\section{Methods}

\section{Data Sources and Study Population}

This was a retrospective cross-sectional analysis of Medicare Current Beneficiaries Survey (MCBS; 2007-2008), the most comprehensive database for the Medicare population. ${ }^{14}$ By linking Medicare claims to survey-reported events, the MCBS's Cost and Use files contain information on sociodemographics, health status, and use and cost of medical services and prescription drugs. The 2007-2008 files were the most recent data available to researchers at the time of this analysis. To determine medication characteristics, the U.S. Food and Drug Administration's (FDA's) Electronic Orange Book (Orange Book) was linked to the MCBS data. ${ }^{15}$ The Orange Book provides comprehensive information about FDA-approved drugs. Three major racial and ethnic groups were included in the study: whites, blacks, and Hispanics. To reduce the heterogeneity of the study population, the study included only homedwelling Medicare beneficiaries who were eligible for Medicare because of age rather than disability or end-stage renal disease.

\section{MTM Eligibility Determination}

The study examined PPACA MTM eligibility criteria in aggregate and for each eligibility criterion. When determining eligibility based on the criterion of "take 4 or more prescribed medications (including over-the-counter medications and dietary supplements)," the authors used information on prescription medication use (information on over-the-counter medications and dietary supplements was not available in MCBS). For the "take a 'high-risk' medication" criterion, patient eligibility was 
determined based on the list of high-risk medications compiled by the Pharmacy Quality Alliance using the 2003 Beers criteria. ${ }^{16}$ For the "have 2 or more chronic diseases" criterion, a list of chronic conditions applicable to the Medicare population assembled by Daniel and Malone (2007) was applied. ${ }^{17}$ Chronic conditions for each participant were identified using a free tool developed by the Agency for Healthcare Research \& Quality, Clinical Classification Software, which aggregates medical conditions and illnesses into 285 mutually exclusive categories. ${ }^{18}$ When determining "a transition of care, or other factors," because the study sample comprised only community-dwelling Medicare beneficiaries, the authors considered any record of a hospitalization or a hospice admission, or admission to any other facility including a nursing home, as "a transition of care."

\section{Outcome Variables}

The main study variable first included "would the patient meet the PPACA MTM eligibility criteria," which was defined as a dummy variable. Health and economic outcomes included health status, health services utilization and costs, and medication use patterns. These measures were selected mainly because MTM has been shown to improve patient health outcomes, reduce health services utilization and costs, and improve patient medication use patterns. ${ }^{4-7}$ Additionally, PPACA also identifies the improvements of these aspects as outcomes to achieve through providing MTM services. ${ }^{13}$ Further, racial and ethnic disparities have been reported on all these variables. ${ }^{19-25}$

Regarding health status, the following aspects were examined: self-perceived health status (classified as good [including excellent, very good, or good] vs. poor [fair or poor]), number of chronic conditions, number of activities of daily living (ADLs), and number of instrumental activities of daily living (IADLs). When studying health services utilization and costs, the authors measured the number and costs of physician visits and emergency room visits as well as the total health care costs. Prescription use pattern was analyzed using generic dispensing ratio (GDR), which was defined as the proportion of prescriptions that were generic among all prescriptions. GDR is a standard performance metric with which pharmacy benefit managers and programs are often evaluated. GDR is used because higher GDRs typically lead to lower total prescription drug costs. ${ }^{26}$

\section{Data Analysis}

Proportions of the population eligible for MTM services on the basis of PPACA MTM eligibility criteria were compared across racial and ethnic groups using a chi-square test; a logistic regression model was used to adjust for population sociodemographic and health characteristics. This study also examined whether racial and ethnic disparities in health and economic outcomes were greater among MTM-ineligible individuals than
MTM-eligible individuals, according to PPACA eligibility criteria. To achieve this objective, a difference-in-differences (DID) model was used. When the authors examined racial disparities, for example, the equation was as follows:

$$
\begin{gathered}
\mathrm{E}[\mathrm{y} \mid \text { Minority, Eligible }]=\mathrm{F}\left[\mathrm{b}_{0}+\mathrm{b}_{1} \text { Minority }+\mathrm{b}_{2} \text { Eligible }+\right. \\
\left.\mathrm{b}_{3} \text { Minority*Eligible }+\mathrm{e}\right]
\end{gathered}
$$

The "y" denotes an outcome variable, "Minority" denotes a dummy variable for blacks, "Eligible" denotes a dummy variable for individuals' eligibility for MTM, and "Minority*Eligible" is an interaction term representing the difference in disparity patterns between MTM-eligible and MTM-ineligible individuals. The "e" in the model is an error term. When the authors estimated the effect of the interaction between the race and ethnicity variables and MTM eligibility and when regression models were nonlinear regressions, they interpreted the interaction term on both the multiplicative term and the additive term. ${ }^{27}$ Both interpretations are equivalent to first calculating the differences between whites and blacks (or between whites and Hispanics) among the MTM-ineligible population and among the MTM-eligible population, and then calculating the difference between the differences. The " $b_{3}$ " provides an estimate on the interactive effect on the multiplicative term. The additive term estimates the difference in marginal effects across racial/ethnic groups between the MTM-ineligible and the MTM-eligible populations. If the coefficient " $b_{3}$ " or the difference in marginal effects across racial/ethnic groups is positive and statistically significant, it will indicate greater racial/ ethnic disparities among the MTM-ineligible than among the MTM-eligible population.

The functional form of the regression model varies according to the types of dependent variables. A logistic regression was used to analyze a binary variable: self-perceived health status; a negative binomial model was used for count variables including the number of ADLs and IADLs, the number of emergency room visits, and the number of physician visits; a Poisson model was used for the number of chronic conditions, because the negative binomial model would not converge for the number of chronic conditions; a generalized linear model with log link function and gamma distribution was used for all cost variables; and an ordinary least-squares regression was used for the GDR. While different models can be used when a dependent variable is a ratio, this study used ordinary leastsquares regression based on previous studies. ${ }^{28,29}$ Number and cost of hospitalization visits could not be analyzed, because all who had hospitalization visits were eligible for MTM services by definition, and interaction terms between race/ethnicity and MTM eligibility could not be estimated.

\section{Independent Variables}

This study used Andersen's Behavioral Model for Health Services Utilization and Iezzoni's Risk Adjustment Model 
Potential Health Implications of Medication Therapy Management Eligibility Criteria in the Patient Protection and Affordable Care Act Across Racial and Ethnic Groups

TABLE 1 Sociodemographic Characteristics Across Racial and Ethnic Groups Among the Study Population

\begin{tabular}{|c|c|c|c|c|c|c|c|}
\hline \multirow[b]{2}{*}{ Variables } & \multirow[b]{2}{*}{ Groups } & \multicolumn{2}{|c|}{ Non-Hispanic Whites } & \multicolumn{2}{|c|}{ Non-Hispanic Blacks } & \multicolumn{2}{|c|}{ Hispanics } \\
\hline & & $\mathbf{n}$ & $\%$ & $\mathbf{n}$ & $\%$ & $\mathbf{n}$ & $\%$ \\
\hline \multirow[t]{3}{*}{$\overline{\text { Age (years) }{ }^{a, b}}$} & $65-74$ & 4,702 & 51.8 & 451 & 56.4 & 435 & 60.4 \\
\hline & $75-84$ & 4,337 & 34.3 & 325 & 32.2 & 283 & 27.4 \\
\hline & $\geq 85$ & 2,122 & 13.9 & 154 & 11.4 & 157 & 12.2 \\
\hline \multirow[t]{2}{*}{ Gender } & Female & 6,149 & 55.4 & 579 & 58.6 & 485 & 56.3 \\
\hline & Male & 5,012 & 44.6 & 351 & 41.4 & 390 & 43.8 \\
\hline \multirow[t]{2}{*}{ Marital status ${ }^{a, b}$} & Not married & 4,993 & 41.9 & 634 & 64.6 & 452 & 48.8 \\
\hline & Married & 6,159 & 58.1 & 296 & 35.4 & 420 & 51.2 \\
\hline \multirow[t]{3}{*}{ Education ${ }^{\mathrm{a}, \mathrm{b}}$} & Lower than high school & 2,379 & 24.4 & 446 & 49.9 & 456 & 56.1 \\
\hline & High school & 3,553 & 39.8 & 233 & 30.3 & 185 & 25.1 \\
\hline & Higher than high school & 3,042 & 35.8 & 146 & 19.8 & 136 & 18.7 \\
\hline \multirow[t]{5}{*}{ Poverty status ${ }^{\mathrm{a}, \mathrm{b}}$} & $100 \%$ FPL & 988 & 8.3 & 320 & 30.2 & 291 & 30.0 \\
\hline & $100 \%-149 \%$ FPL & 1,447 & 12.0 & 168 & 16.8 & 187 & 20.9 \\
\hline & $150 \%-199 \%$ FPL & 1,357 & 11.6 & 115 & 13.5 & 106 & 13.1 \\
\hline & $200 \%-300 \%$ FPL & 2,507 & 22.2 & 160 & 17.9 & 115 & 14.1 \\
\hline & Higher than 300\% FPL & 4,862 & 46.0 & 167 & 21.7 & 176 & 21.9 \\
\hline \multirow[t]{2}{*}{ Medicaid ${ }^{a, b}$} & No & 10,236 & 92.7 & 614 & 70.5 & 511 & 61.8 \\
\hline & Yes & 925 & 7.3 & 316 & 29.5 & 364 & 38.2 \\
\hline \multirow[t]{4}{*}{ U.S. census region ${ }^{\mathrm{a}, \mathrm{b}}$} & Northeast & 1,966 & 19.6 & 158 & 19.3 & 94 & 13.6 \\
\hline & Midwest & 2,903 & 25.2 & 141 & 14.9 & 65 & 8.1 \\
\hline & South & 4,544 & 38.6 & 560 & 57.0 & 264 & 33.8 \\
\hline & West & 1,732 & 16.6 & 66 & 8.8 & 296 & 44.6 \\
\hline \multirow[t]{2}{*}{ Metropolitan statistical area $\mathrm{a}^{\mathrm{a}, \mathrm{b}}$} & No & 3,507 & 28.1 & 195 & 17.5 & 99 & 8.7 \\
\hline & Yes & 7,638 & 71.9 & 732 & 82.5 & 774 & 91.3 \\
\hline \multirow[t]{5}{*}{ Self-perceived health statusa,b } & Excellent & 1,888 & 18.8 & 102 & 11.6 & 101 & 12.7 \\
\hline & Very good & 3,539 & 32.2 & 213 & 24.5 & 216 & 24.0 \\
\hline & Good & 3,498 & 31.0 & 336 & 36.8 & 299 & 34.1 \\
\hline & Fair & 1,589 & 13.0 & 200 & 20.6 & 205 & 23.2 \\
\hline & Poor & 575 & 4.9 & 67 & 6.5 & 50 & 5.9 \\
\hline
\end{tabular}

aP $<0.050$ for the difference between non-Hispanic whites (whites) and non-Hispanic blacks.

${ }^{b} P<0.050$ for the difference between whites and Hispanics.

$F P L=$ federal poverty level.

to categorize the independent variables. ${ }^{30,31}$ According to Andersen's Behavioral Model, the utilization of health services is a function of (a) predisposing, (b) enabling, and (c) need factors. Predisposing factors included race, ethnicity, age, gender, and marital status; enabling factors included socioeconomic status, education, health insurance, and region of residence; and need factors included self-perceived health status and a risk adjustment summary score. The risk adjustment summary score was derived from the Diagnostic Cost Group/Hierarchical Coexisting Condition model, a free software available on the website of the Centers for Medicare \& Medicaid Services (CMS). ${ }^{32}$ Iezzoni's Risk Adjustment Model was used when analyzing health status. This model categorizes dimensions of risk into sociodemographic variables and health status measures. ${ }^{31}$ All independent variables previously mentioned were included in the models for health status except health status measures.

The complex survey design of MCBS, including primary sampling units, strata, and cross-sectional full sample weights, was accounted for in all analyses. Data analyses were con- ducted using Stata software package 12.0 (StataCorp, College Station, TX) and SAS software package 9.3 (SAS Institute Inc., Cary, NC). The statistical significance level was set a priori at 0.05 . The study received institutional review board approval at the lead author's institution.

\section{Results}

The sample consisted of 12,966 Medicare beneficiaries (weighted to $51,635,149$ ). Of these, 11,161 were white (weighted to $44,264,118 ; 85.7 \%$ ), 930 were black (weighted to $3,734,991$; $7.2 \%$ ), and 875 were Hispanic (weighted to $3,636,039 ; 7.1 \%$ ). In comparison to whites, minorities were younger in age, less likely to be married, less likely to have higher education, more likely to belong to lower income categories, more likely to have Medicaid, and more likely to live in metropolitan areas $(P<0.050$; Table 1). Minorities were more likely to perceive their health status as either fair or poor rather than excellent, very good, or good compared with whites. With the exception of gender, 
Potential Health Implications of Medication Therapy Management Eligibility Criteria in the Patient Protection and Affordable Care Act Across Racial and Ethnic Groups

\begin{tabular}{|c|c|c|c|c|}
\hline Analyses & Groups & Number Eligible & Number Eligible Weighted & Proportion Eligible (\%) \\
\hline \multirow[t]{3}{*}{ PPACA $^{a}$} & Whites & 9,992 & $38,239,677$ & 86.4 \\
\hline & Blacks & 825 & $3,221,385$ & 86.3 \\
\hline & Hispanics & 733 & $2,931,169$ & 80.6 \\
\hline \multirow[t]{3}{*}{$\geq 4$ of drugs $\mathrm{a}, \mathrm{b}$} & Whites & 7,897 & $28,421,012$ & 64.2 \\
\hline & Blacks & 633 & $2,235,761$ & 59.9 \\
\hline & Hispanics & 557 & $1,995,408$ & 54.9 \\
\hline \multirow[t]{3}{*}{$\geq 2$ of chronic conditions ${ }^{a}$} & Whites & 9,454 & $36,075,724$ & 81.5 \\
\hline & Blacks & 788 & $3,061,203$ & 82.0 \\
\hline & Hispanics & 659 & $2,634,621$ & 72.5 \\
\hline \multirow[t]{3}{*}{$\geq 1$ of high-risk medication ${ }^{a}$} & Whites & 2,044 & $7,383,933$ & 16.7 \\
\hline & Blacks & 141 & 507,726 & 13.6 \\
\hline & Hispanics & 130 & 468,597 & 12.9 \\
\hline \multirow[t]{3}{*}{$\geq 1$ of transition of care ${ }^{a}$} & Whites & 2,276 & $8,081,977$ & 18.3 \\
\hline & Blacks & 184 & 645,792 & 17.3 \\
\hline & Hispanics & 142 & 481,172 & 13.2 \\
\hline
\end{tabular}

the differences between whites and racial and ethnic minorities were significant for all patient characteristics (Table 1). The differences in gender distribution were not significant between whites and blacks or whites and Hispanics.

Both bivariate and multivariate analyses were conducted to examine whether whites would be more likely to meet PPACA MTM eligibility criteria than blacks and Hispanics among the Medicare population in 2007-2008 (Table 2). Of the study sample, 9,992 whites (86.4\%), 825 blacks (86.3\%), and 733 Hispanics (80.6\%) were eligible for MTM. The difference between whites and Hispanics was significant, but the difference between whites and blacks was not. When examining each individual eligibility criterion, the authors found that the difference between whites and blacks was statistically significant for the drug use criterion, and the difference between whites and Hispanics was statistically significant for all 4 PPACA eligibility criteria. After adjusting for sociodemographic and health status characteristics in the multivariate analysis, significant disparity in eligibility for MTM services was found between Hispanics and whites (odds ratio $[\mathrm{OR}]=0.59 ; 95 \%$ confidence interval $[\mathrm{CI}]=0.43-0.82$; Table 3 ) but not between blacks and whites (OR=0.78; 95\% CI=0.55-1.09; Table 3).

\section{Disparity Implications of MTM Eligibility Criteria Between Whites and Blacks}

The difference in proportions of whites and blacks who reported having self-perceived good health status among MTM-ineligible beneficiaries was 5.8\% (97.2\% vs. $91.4 \%$ for whites and blacks, respectively; $P<0.050$; Table 4). Among the MTM-eligible beneficiaries, this difference was $10.2 \%$
(78.5\% vs. 68.3\%; $P<0.050$; Table 4). The DID between MTMineligible and MTM-eligible beneficiaries was $-4.4 \%(P=0.050$; Table 4). The disparities seem to be smaller among the MTMineligible than the MTM-eligible individuals.

However, the adjusted analysis had opposite findings. In the multivariate logistic regression analyses, the interaction term between blacks and MTM eligibility criteria was found to be positive and significant after adjusting for all patient confounders (interaction effect $=3.68 ; P=0.018 ; 95 \% \mathrm{CI}=1.25-10.80 ;$ Table 5). On the additive term, the difference in marginal effects was also higher among the MTM-ineligible beneficiaries compared with the MTM-eligible beneficiaries in the adjusted analysis (difference in marginal effects $=35.89 ; P=0.003 ; 95 \%$ $\mathrm{CI}=$ 12.44-59.34; Table 5).

Regarding the number of chronic conditions, both among MTM-ineligible and MTM-eligible populations, whites and blacks had a similar number of chronic conditions (Table 4). The DID between MTM-ineligible and MTM-eligible populations was not significant (DID $=[-0.05] ; P=0.173$; Table 4). In the multivariate Poisson regression analyses, the interaction term between blacks and MTM eligibility criteria was not found to be significant (Table 5). On the additive term, the difference in marginal effects was lower among MTM-ineligible than MTM-eligible beneficiaries in the adjusted analysis (difference in marginal effects $=-0.21 ; P=0.070 ; 95 \% \mathrm{CI}=[-0.44]$ 0.02; Table 5).

Among the MTM-ineligible population, whites had a similar number of ADLs and IADLs as blacks, while among the MTM-eligible population, whites had a lower number of ADLs and IADLs than blacks (Table 4). Disparities in ADLs and 
Potential Health Implications of Medication Therapy Management Eligibility Criteria in the Patient Protection and Affordable Care Act Across Racial and Ethnic Groups

TABLE 3 Racial and Ethnic Disparities in Meeting Eligibility Criteria for Medication Therapy Management Services According to the Patient Protection and Affordable Care Act Based on Logistic Regression ${ }^{\text {a }}$

\begin{tabular}{|c|c|c|c|c|}
\hline & Estimate & $P$ Value & OR & $95 \%$ CI for OR \\
\hline Intercept & -7.98 & $<0.0001$ & - & - \\
\hline Non-Hispanic whites & - & - & - & - \\
\hline Non-Hispanic blacks & -0.25 & 0.147 & 0.78 & $0.55-1.09$ \\
\hline Hispanics & -0.53 & 0.002 & 0.59 & $0.43-0.82$ \\
\hline Age (years) & 0.12 & $<0.0001$ & 1.13 & $1.07-1.19$ \\
\hline Female & - & - & - & - \\
\hline Male & -0.34 & 0.003 & 0.71 & $0.57-0.89$ \\
\hline Not married & - & - & - & - \\
\hline Married & 0.20 & 0.045 & 1.22 & $1.01-1.48$ \\
\hline Lower than high school & - & - & - & - \\
\hline High school & 0.06 & 0.561 & 1.07 & $0.86-1.32$ \\
\hline Higher than high school & 0.15 & 0.250 & 1.16 & $0.90-1.49$ \\
\hline $100 \%$ FPL & - & - & - & - \\
\hline $100 \%-149 \%$ FPL & 0.11 & 0.443 & 1.11 & $0.85-1.47$ \\
\hline 150\%-199\% FPL & 0.18 & 0.283 & 1.19 & $0.87-1.64$ \\
\hline $200 \%-300 \%$ FPL & 0.08 & 0.573 & 1.09 & $0.82-1.44$ \\
\hline Higher than 300\% FPL & 0.39 & 0.012 & 1.48 & $1.09-2.00$ \\
\hline Non-Medicaid & - & - & - & - \\
\hline Medicaid & 0.32 & 0.313 & 1.38 & $0.74-2.56$ \\
\hline Northeast & - & - & - & - \\
\hline Midwest & 0.20 & 0.291 & 1.22 & $0.84-1.78$ \\
\hline South & 0.26 & 0.035 & 1.30 & $1.02-1.65$ \\
\hline West & -0.09 & 0.552 & 0.91 & $0.67-1.24$ \\
\hline Non-MSA & - & - & - & - \\
\hline$\overline{\mathrm{MSA}}$ & -0.16 & 0.154 & 0.85 & $0.68-1.06$ \\
\hline Excellent self-perceived health status & - & - & - & - \\
\hline Very good self-perceived health status & 0.79 & $<0.0001$ & 2.20 & $1.83-2.66$ \\
\hline Good self-perceived health status & 1.64 & $<0.0001$ & 5.16 & $4.17-6.37$ \\
\hline Fair self-perceived health status & 2.77 & $<0.0001$ & 15.93 & $10.00-25.36$ \\
\hline Poor self-perceived health status & 3.29 & $<0.0001$ & 26.93 & $12.40-58.51$ \\
\hline Risk adjustment summary score & -0.88 & 0.527 & 0.42 & $0.03-6.31$ \\
\hline
\end{tabular}

a Number of population included in the analysis was 10,486, weighted to 40,967,373. Wald's statistic: $795.75(P<0.0001)$.

$C I=$ confidence interval; $F P L=$ federal poverty level; $M S A=$ metropolitan statistical area; $O R=$ odds ratio.

IADLs were greater among MTM-ineligible beneficiaries than MTM-eligible beneficiaries on the additive term (Table 5). When analyzing ADLs on the additive term, the authors found that the difference in ADLs between whites and blacks was greater among MTM-ineligible than MTM-eligible individuals, according to the adjusted analysis (difference in marginal effects $=0.26 ; P=0.002 ; 95 \% C I=0.09-0.43$; Table 5); also on the additive term, the difference in IADLs between whites and blacks was greater among the MTM-ineligible beneficiaries compared with the MTM-eligible beneficiaries in the adjusted analysis (difference in marginal effects $=0.44 ; P<0.001 ; 95 \%$ $\mathrm{CI}=0.25-0.63$; Table 5).

The number and costs of physician visits exhibited higher values among whites than blacks among both MTM-ineligible and MTM-eligible populations (Table 4). For the number of physician visits, the difference in marginal effects was found to be lower among MTM-ineligible than MTM-eligible beneficia- ries in the adjusted model (difference in marginal effects $=-3.43$; $P=0.025 ; 95 \% \mathrm{CI}=[-6.43]-[-0.42]$; Table 5). When examining the costs of physician visits, the authors found the difference in marginal effects between whites and blacks was lower among the MTM-ineligible group than the MTM-eligible group in the adjusted analysis (difference in marginal effects $=-688.33$; $P=0.006 ; 95 \% \mathrm{CI}=[-1,180.05]-[-196.60]$; Table 5). For all other outcome measures, no statistical significant findings were made for the interaction effects between MTM eligibility criteria and dummy variables for blacks (Table 5).

\section{Disparity Implications of MTM Eligibility Criteria Between Whites and Hispanics}

The difference in the proportions of whites and Hispanics who reported having self-perceived good health status among MTM-ineligible beneficiaries was 5.0\% (97.2\% vs. $92.2 \%$ for whites and Hispanics, respectively; $P<0.050$; Table 4). Among 
TABLE 4 Descriptive Results for Outcomes Across Racial and Ethnic Groups for MTM-Ineligible and MTMEligible Individuals Based on the Patient Protection and Affordable Care Act Eligibility Criteria

\begin{tabular}{|c|c|c|c|c|c|c|c|c|}
\hline Variables & $\begin{array}{c}\text { MTM } \\
\text { Eligibility }\end{array}$ & Whites & Blacks & Difference $^{a}$ & DID $^{b}$ & Hispanics & Difference $^{a}$ & DID $^{b}$ \\
\hline \multicolumn{9}{|l|}{ Health status } \\
\hline \multirow[t]{2}{*}{ Self-perceived good health status } & ineligible & $97.2 \%$ & $91.4 \%$ & $5.8 \%^{c}$ & $-4.4 \%(P=0.001)$ & $92.2 \%$ & $5.0 \%{ }^{c}$ & $-6.9 \%(P=0.005)$ \\
\hline & eligible & $78.5 \%$ & $68.3 \%$ & $10.2 \%^{\mathrm{c}}$ & & $66.6 \%$ & $11.9 \%^{\mathrm{c}}$ & \\
\hline \multirow[t]{2}{*}{ Number of chronic diseases } & ineligible & 0.57 & 0.57 & 0.00 & $-0.05(P=0.173)$ & 0.62 & -0.05 & $-0.48(P<0.001)$ \\
\hline & eligible & 4.00 & 3.95 & 0.05 & & 3.57 & $0.43^{c}$ & \\
\hline \multirow[t]{2}{*}{ ADLs } & ineligible & 0.11 & 0.09 & 0.02 & $0.30(P=0.023)$ & 0.14 & -0.03 & $0.41(P<0.001)$ \\
\hline & eligible & 0.64 & 0.92 & $-0.28^{c}$ & & 1.08 & $-0.44^{c}$ & \\
\hline \multirow[t]{2}{*}{ IADLs } & ineligible & 0.17 & 0.14 & 0.03 & $0.47(P<0.001)$ & 0.18 & -0.01 & $0.49(P=0.001)$ \\
\hline & eligible & 0.87 & 1.31 & $-0.44 c$ & & 1.37 & $-0.50^{c}$ & \\
\hline \multicolumn{9}{|c|}{ Health services utilization and costs } \\
\hline \multirow[t]{2}{*}{ Number of physician visits } & ineligible & 7.34 & 4.60 & $2.74^{\mathrm{c}}$ & $-2.06(P=0.197)$ & 5.60 & $1.74 \mathrm{c}$ & $-3.00(P=0.028)$ \\
\hline & eligible & 31.25 & 26.45 & $4.80^{\mathrm{c}}$ & & 26.51 & $4.74 \mathrm{c}$ & \\
\hline \multirow[t]{2}{*}{ Costs of physician visits } & ineligible & $1,127.03$ & 520.09 & $606.94 \mathrm{c}$ & $-244.64(P=0.561)$ & 762.91 & $364.12^{\mathrm{c}}$ & $-34.95(P=0.431)$ \\
\hline & eligible & $4,254.16$ & $3,402.58$ & $851.58^{\mathrm{c}}$ & & $3,855.09$ & 399.07 & \\
\hline \multirow[t]{2}{*}{ Number of emergency visits } & ineligible & 0.03 & 0.07 & -0.04 & $-0.04(P=0.189)$ & 0.00 & $0.03^{c}$ & 0.03 \\
\hline & eligible & 0.18 & 0.18 & 0.00 & & 0.18 & 0.00 & \\
\hline \multirow[t]{2}{*}{ Costs of emergency visits } & ineligible & 13.51 & 13.50 & 0.01 & $39.94(P=0.567)$ & 0.00 & $13.51^{\mathrm{c}}$ & -26.03 \\
\hline & eligible & 99.98 & 139.91 & -39.93 & & 60.44 & $39.54^{c}$ & \\
\hline \multirow[t]{2}{*}{ Total costs } & ineligible & $2,234.89$ & $1,243.91$ & $990.98^{c}$ & $587.78(P=0.698)$ & $1,862.33$ & 372.56 & $-309.54(P=0.169)$ \\
\hline & eligible & $13,624.51$ & $13,221.31$ & 403.20 & & $12,942.41$ & 682.10 & \\
\hline \multicolumn{9}{|l|}{ Medication use patterns } \\
\hline \multirow[t]{2}{*}{ Generic dispensing ratio } & ineligible & 0.23 & 0.18 & 0.05 & $0.05(P=0.587)$ & 0.18 & 0.05 & $0.02(P=0.750)$ \\
\hline & eligible & 0.52 & 0.52 & 0.00 & & 0.49 & 0.03 & \\
\hline
\end{tabular}

a Difference $=($ MTM-ineligible whites-MTM-ineligible blacks/Hispanics) or (MTM-eligible whites-MTM-eligible blacks/Hispanics).

${ }^{b}$ DID $=$ difference-in-differences $=($ MTM-ineligible whites-MTM-ineligible blacks/Hispanics) -(MTM-eligible whites-MTM-eligible blacks/Hispanics).

${ }^{c} P<0.050$.

ADLs=activities of daily living; IADLs = instrumental activities of daily living; MTM= medication therapy management.

MTM-eligible beneficiaries, this difference was $11.9 \%$ (78.5\% vs. $66.6 \%$ for whites and Hispanics, respectively; $P<0.050$; Table 4). The DID between MTM-ineligible and MTM-eligible beneficiaries was $-6.9 \%(P=0.005$; Table 4$)$. The interaction term between Hispanics and MTM eligibility was not significant in the adjusted model on the multiplicative term. The difference in marginal effects was higher among MTM-ineligible beneficiaries compared with MTM-eligible beneficiaries in the adjusted analysis (difference in marginal effects $=30.20$; $P=0.017$; 95\% CI = 5.31-55.10; Table 5).

When analyzing disparity patterns in the number of chronic conditions, it was found that whites had a higher number of chronic conditions than Hispanics only among the MTM-eligible population, and the disparity was significantly smaller among the MTM-ineligible than the MTMeligible groups (Table 4). Multivariate analyses had similar findings. On the multiplicative term, the interaction term between Hispanics and MTM eligibility was significant in the adjusted model (coefficient $=-0.26$; rate ratio $=0.77 ; P=0.030$; 95\% CI=0.61-0.98; Table 5). The difference in marginal effects for Hispanics and whites was smaller among the MTM-ineligible than the MTM-eligible population based on the adjusted analysis (difference in marginal effects $=-0.49$; $P<0.001 ; 95 \% \mathrm{CI}=[-0.73]-[-0.24]$; Table 5).

Hispanics had higher numbers of ADLs than whites among the MTM-eligible population and similar numbers of ADLs as whites among the MTM-ineligible population, and the disparity in ADLs was greater among MTM-ineligible beneficiaries than MTM-eligible beneficiaries (Table 4). This pattern was also found in the adjusted analysis on the additive term (difference in marginal effects $=0.51 ; P=0.001 ; 95 \% C I=0.22-0.79$; Table 5). The analysis of IADLs showed a similar pattern in the adjusted analysis (difference in marginal effects $=0.44$; $P=0.005 ; 95 \% \mathrm{CI}=0.14-0.74$; Table 5).

Regarding physician visits, Hispanics had a lower number of physician visits than whites among both the MTM-ineligible and MTM-eligible population (Table 4). The disparity was smaller among the MTM-ineligible than the MTM-eligible population (Table 4). The difference in marginal effects for Hispanics and whites was smaller among the MTM-ineligible 
Potential Health Implications of Medication Therapy Management Eligibility Criteria in the Patient Protection and Affordable Care Act Across Racial and Ethnic Groups

TABLE 5 Interaction Effects Across Racial and Ethnic Groups and Medication Therapy Management Eligibility Categories Based on the Patient Protection and Affordable Care Act (Adjusted Model)

\begin{tabular}{|c|c|c|c|c|c|c|c|}
\hline \multirow[b]{2}{*}{ Variables } & \multicolumn{4}{|c|}{ Multiplicative Effects } & \multicolumn{3}{|c|}{ Marginal Effects } \\
\hline & Coef. & $\begin{array}{l}\text { Interac. } \\
\text { Effects }\end{array}$ & $P$ Value & $95 \% \mathrm{CI}$ & DID & $P$ Value & $95 \%$ CI \\
\hline \multicolumn{8}{|l|}{ Health status } \\
\hline Self-perceived good health status & 1.30 & 3.68 & 0.018 & $1.25-10.80$ & 35.89 & 0.003 & $12.44-59.34$ \\
\hline Number of chronic conditions & -0.14 & 0.87 & 0.254 & $0.68-1.11$ & -0.21 & 0.070 & $(-0.44)-0.02$ \\
\hline Number of ADLs & 0.32 & 1.38 & 0.486 & $0.56-3.41$ & 0.26 & 0.002 & $0.09-0.43$ \\
\hline Number of IADLs & 0.77 & 2.15 & 0.114 & $0.83-5.58$ & 0.44 & $<0.001$ & $0.25-0.63$ \\
\hline \multicolumn{8}{|l|}{ Health services utilization and costs } \\
\hline Number of physician visits & 0.20 & 1.22 & 0.292 & $0.84-1.78$ & -3.43 & 0.025 & $(-6.43)-(-0.42)$ \\
\hline Costs of physician visits & 0.31 & 1.37 & 0.187 & $0.86-2.18$ & -688.33 & 0.006 & $(-1,180.05)-(-196.60)$ \\
\hline Number of emergency room visits & -1.00 & 0.37 & 0.054 & $0.13-1.02$ & -0.04 & 0.202 & $(-0.11)-0.02$ \\
\hline Costs of emergency room visits & 0.21 & 1.24 & 0.695 & $0.43-3.59$ & 20.54 & 0.430 & $(-30.09)-71.17$ \\
\hline Total costs & 0.25 & 1.28 & 0.321 & $0.78-2.09$ & $-1,031.64$ & 0.280 & $(-2,900.68)-837.40$ \\
\hline \multicolumn{8}{|l|}{ Medication use patterns } \\
\hline Generic dispensing ratio & 0.04 & - & 0.380 & $(-0.05)-0.14$ & - & - & - \\
\hline \multicolumn{8}{|c|}{ Panel 2. Comparison Group: Whites Versus Hispanics } \\
\hline \multicolumn{8}{|l|}{ Health status } \\
\hline Self-perceived good health status & 0.70 & 2.02 & 0.136 & $0.80-5.10$ & 30.20 & 0.017 & $5.31-55.10$ \\
\hline Number of chronic conditions & -0.26 & 0.77 & 0.030 & $0.61-0.98$ & -0.49 & $<0.001$ & $(-0.73)-(-0.24)$ \\
\hline Number of ADLs & 0.10 & 1.11 & 0.796 & $0.50-2.48$ & 0.51 & 0.001 & $0.22-0.79$ \\
\hline Number of IADLs & 0.06 & 1.06 & 0.895 & $0.43-2.64$ & 0.44 & 0.005 & $0.14-0.74$ \\
\hline \multicolumn{8}{|l|}{ Health services utilization and costs } \\
\hline Number of physician visits & -0.18 & 0.84 & 0.449 & $0.53-1.33$ & -5.73 & 0.007 & $(-9.89)-(-1.57)$ \\
\hline Costs of physician visits & -0.34 & 0.71 & 0.275 & $0.39-1.31$ & $-1,116.32$ & 0.002 & $(-1,832.37)-(-400.28)$ \\
\hline Number of emergency room visits & - & - & - & - & - & - & - \\
\hline Costs of emergency room visits & - & - & - & - & - & - & - \\
\hline Total costs & -0.39 & 0.68 & 0.132 & $0.40-1.13$ & $-2,584.39$ & 0.027 & $(-4,878.69)-(-290.08)$ \\
\hline \multicolumn{8}{|l|}{ Medication use patterns } \\
\hline Generic dispensing ratio & 0.03 & - & 0.364 & $(-0.03)-0.09$ & - & - & - \\
\hline
\end{tabular}

group than the MTM-eligible group in the adjusted analysis (difference in marginal effects $=-5.73 ; P=0.007 ; 95 \%$ $\mathrm{CI}=[-9.89]-[-1.57] ;$ Table 5).

When analyzing costs of physician visits, the authors also found that the difference in marginal effects for Hispanics and whites was smaller among the MTM-ineligible group than the MTM-eligible group in the adjusted analysis (difference in marginal effects $=-1,116.32 ; P=0.002 ; 95 \% \mathrm{CI}=[-1,832.37]$ -[-400.28]; Table 5). Similar patterns of lower disparities among the MTM-ineligible group than the MTM-eligible group were found for total health care costs (difference in marginal effects $=-2,584.39 ; \quad P=0.027 ; \quad 95 \% C I=[-4,878.69]-[-290.08])$; Table 5).

While analyzing the number and costs of emergency room visits, the authors found that the models could not converge because Hispanics among the MTM-ineligible population did not have any emergency room visits or incur emergency room costs. When the authors analyzed other outcome measures, they found no statistically significant findings for the interaction effects between MTM eligibility criteria and dummy variables for Hispanics (Table 5).

\section{Discussion}

By analyzing the most comprehensive database available for the Medicare population, the authors of this study found that Hispanics would be less likely than whites to be eligible for MTM services, according to the criteria stipulated in the PPACA among the Medicare population; the difference between blacks and whites was not significant. The present study revealed a mixed picture of the potential effects of PPACA MTM eligibility criteria on existing racial and ethnic disparities. The original hypothesis, that there would be greater racial and ethnic disparities among the MTM-ineligible population than the MTM-eligible population, was supported in the 
analysis of self-perceived health status, ADLs, and IADLs. Therefore, PPACA MTM eligibility criteria would likely aggravate existing racial and ethnic disparities in health outcomes.

However, when analyzing the number of chronic conditions, the number and costs of physician visits and total health care costs, the authors found lower racial and ethnic disparities among the MTM-ineligible than the MTM-eligible population. Because the number of chronic conditions can be considered a measure for health services utilization along with the number and costs of physician visits, PPACA MTM eligibility criteria may help to remediate racial and ethnic disparities in the number and costs of physician visits and in general health services utilization. While it is difficult to pinpoint the exact reasons for the differential effects of PPACA MTM eligibility criteria on disparities in health status versus disparities in health services utilization, one plausible explanation for the above pattern is that the fundamental basis of these MTM eligibility criteria rests on health services utilization, rather than health status.

First documented in the 1985 Heckler Report, racial and ethnic disparities have been found to be pervasive and persistent in the United States. ${ }^{33}$ When PPACA was signed into law in March 2010, it was poised to address health disparities in critical ways. However, it has also been recognized that quality improvement provisions in PPACA might not benefit all segments of the population equally. ${ }^{34}$ Therefore, it is important to evaluate the effectiveness of PPACA in achieving its mission. Although great interest has been generated in conducting such research, PPACA's MTM provisions have received little attention to date. This study projected the effects of the MTM eligibility criteria as defined in PPACA on racial and ethnic disparities in health outcomes. Future studies should revisit this topic following complete implementation of the criteria to determine their real-world impact.

The shortcomings of existing MTM eligibility criteria have been documented in the literature. Stuart et al. recently reported that current MTM eligibility criteria exclude beneficiaries with problematic medication use patterns and target those with higher adherence. ${ }^{35}$ Such a finding is not surprising, because patients who use more prescription medications (adherers) are more likely to meet use-based eligibility criteria. Additionally, the same group of researchers suggested aligning MTM eligibility with a metric such as "potentially preventable future costs," with the purpose of reducing spending and improving quality of care. ${ }^{36}$

In January 2014, CMS proposed a new set of rules for Part D plans, acknowledging the limitations of the current MTM eligibility criteria, including those reported by Wang et al. ${ }^{8,9,37}$ CMS proposed to expand MTM to all individuals who have at least two chronic conditions, have two Part D-covered drugs, and exceed a drug cost threshold of $\$ 620.40$. Further research is needed to confirm that the proposed criteria will have the desired effects of increasing access to MTM services among Medicare beneficiaries and decreasing racial and ethnic dis- parities. Additionally, future studies may devise other innovative eligibility criteria to achieve the desired effects of increased equity, effectiveness, and efficiency.

\section{Limitations}

While this study provided valuable findings, it has limitations. The analysis is based on policy scenarios rather than actual patient MTM enrollment data. However, this is a necessary compromise because PPACA MTM criteria have not been implemented. Indeed, by examining a policy scenario, this study is able to guide policy development by identifying the strengths and weaknesses of policies before they are implemented. Other limitations pertain to information available in the MCBS. For example, over-the-counter medications were not included in the analysis, although these were considered part of PPACA MTM eligibility criteria.

\section{Conclusions}

PPACA MTM eligibility criteria may have mixed effects on existing racial and ethnic disparities. Hispanics would be significantly less likely than whites to qualify for MTM services, according to MTM eligibility criteria stipulated in the PPACA. While PPACA MTM eligibility criteria may aggravate existing racial and ethnic disparities in health outcomes, they appear to remediate racial and ethnic disparities in health services utilization. Alternative MTM eligibility criteria may be needed to improve the efficiency and equity of access to Medicare Part D MTM programs.

\section{Authors}

JUNLING WANG, PhD, is Professor; YANRU QIAO, MS, is Research Assistant; JOELLEN JARRETT-JAMISON, BS, is PharmD Student, Class of 2015; CHRISTINA A. SPIVEY, PhD, is Assistant Professor; SHELLEY I. WHITE-MEANS, PhD, is Professor and Director, Consortium for Health Education, Economic Empowerment and Research (CHEER); and MARIE CHISHOLM-BURNS, PharmD, MPH, MBA, FCCP, FASHP, is Dean and Professor, University of Tennessee College of Pharmacy, Memphis. JIM Y WAN, PhD, is Associate Professor, Department of Preventive Medicine E Urology, and SAMUEL DAGOGO-JACK, MD, FRCP, is Mullins Professor and Director, Division of Endocrinology, Diabetes \& Metabolism, and Director, Clinical Research Center, Health Science Center, University of Tennessee College of Medicine, Memphis. WILLIAM C. CUSHMAN, MD, is Professor, Department of Preventive Medicine and Physiology, University of Tennessee College of Medicine, and Chief, Preventive Medicine Section, Veterans Affairs Medical Center, Memphis. YA-CHEN TINA SHIH, $\mathrm{PhD}$, is Professor of Health Economics and Chief, Section of Cancer Economics and Policy, Department of Health Services Research, University of Texas MD Anderson Center, Houston.

AUTHOR CORRESPONDENCE: Junling Wang, PhD, MS, Professor, Department of Clinical Pharmacy, University of Tennessee College of Pharmacy, 881 Madison Ave., Rm. 221, Memphis, TN 38163.

Tel.: 901.448.3601; Fax: 901.448.4731; E-mail: jwang26@uthsc.edu. 


\section{DISCLOSURES}

This project was funded by grant R01AG040146 from the National Institute on Aging. The content is solely the responsibility of the authors and does not necessarily represent the official views of the National Institute on Aging or the National Institutes of Health.

Study concept and design were primarily contributed by Wang, Shih, and Dagogo-Jack, with assistance from the rest of the authors. Wang had primary responsibility for data collection, along with Qiao, with assistance from Wan. Data interpretation was primarily the work of Qiao, Wan, and ChisholmBurns, assisted by the rest of the authors. The manuscript was written by Wang, Qiao, and Jarrett-Jamison, with assistance from the rest of the authors, and revised by Spivey, White-Means, and Cushman, with assistance from the rest of the authors.

\section{ACKNOWLEDGMENTS}

The authors would like to acknowledge the research assistance provided by Joshua Bell; Christine Li; Kiraat D. Munshi, MS; and David Seebek.

\section{REFERENCES}

1. Ernst FR, Grizzle AJ. Drug-related morbidity and mortality: updating the cost-of-illness model. J Am Pharm Assoc (Wash). 2001;41(2):192-99.

2. Petrone K, Katz P. Approaches to appropriate drug prescribing for the older adult. Prim Care. 2005;32(3):755-75.

3. Centers for Medicare \& Medicaid Services (CMS), HHS. Medicare program; Medicare prescription drug benefit. Final rule. Fed Regist. 2005;70(18):4193-585

4. Bunting BA, Smith BH, Sutherland SE. The Asheville Project: clinical and economic outcomes of a community-based long-term medication therapy management program for hypertension and dyslipidemia. J Am Pharm Assoc (2003). 2008;48(1):23-31.

5. Cranor CW, Bunting BA, Christensen DB. The Asheville Project: longterm clinical and economic outcomes of a community pharmacy diabetes care program. J Am Pharm Assoc (Wash). 2003;43(2):173-84.

6. Etemad LR, Hay JW. Cost-effectiveness analysis of pharmaceutical care in a Medicare drug benefit program. Value Health. 2003;6(4):425-35.

7. Lee JK, Grace KA, Taylor AJ. Effect of a pharmacy care program on medication adherence and persistence, blood pressure, and low-density lipoprotein cholesterol: a randomized controlled trial. JAMA. 2006;296(21):2563-71.

8. Wang J, Mullins CD, Brown LM, et al. Disparity implications of Medicare eligibility criteria for medication therapy management services. Health Serv Res. 2010;45(4):1061-82.

9. Wang J, Qiao Y. Historical trend of disparity implications of Medicare MTM eligibility criteria. Res Social Adm Pharm. 2013;9(6):758-69.

10. Briesacher B, Limcangco R, Gaskin D. Racial and ethnic disparities in prescription coverage and medication use. Health Care Financ Rev. 2003;25(2):63-76.

11. Wang J, Zuckerman IH, Miller NA, Shaya FT, Noel JM, Mullins CM. Utilizing new prescription drugs: disparities among non-Hispanic whites, nonHispanic blacks, and Hispanic whites. Health Serv Res. 2007;42(4):1499-519.

12. Wang J, Qiao Y, Tina Shih YC, et al. Potential health implications of racial and ethnic disparities in meeting MTM eligibility criteria. Res Social Adm Pharm. 2014;10(1):106-25.

13. Office of the Legislative Counsel. Compilation of Patient Protection and Affordable Care Act (as amended through May 1, 2010). Available at: http://www.leahy.senate.gov/imo/media/doc/Affordable\%20Care $\% 20$ Act $\% 20$ Full\%20Text.pdf. Accessed September 19, 2015.

14. Centers for Medicare \& Medicaid Services. Medicare Current Beneficiary Survey (MCBS). Available at: https://www.cms.gov/Research-StatisticsData-and-systems/Research/MCBS/index.html?redirect=/MCBS/. Accessed September 19, 2015
15. U.S. Food and Drug Administration. Orange Book Data Files. Available at: http://www.fda.gov/drugs/informationondrugs/ucml29689.htm. Accessed September 19, 2015.

16. Fick DM, Cooper JW, Wade WE, Waller JL, Maclean JR, Beers MH. Updating the Beers criteria for potentially inappropriate medication use in older adults: results of a U.S. consensus panel of experts. Arch Intern Med. 2003;163(22):2716-24

17. Daniel GW, Malone DC. Characteristics of older adults who meet the annual prescription drug expenditure threshold for medicare medication therapy management programs. J Manag Care Pharm. 2007;13(2):142-54. Available at: http://amcp.org/data/jmcp/pl42-54.pdf.

18. Elixhauser A, Steiner C, Palmer L. Clinical Classifications Software (CCS), 2014. U.S. Agency for Healthcare Research and Quality. Available at: https://www.hcup-us.ahrq.gov/toolssoftware/ccs/CCSUsersGuide.pdf. Accessed September 26, 2015.

19. Gornick ME. The association of race/socioeconomic status and use of Medicare services. A little-known failure in access to care. Ann N Y Acad Sci. 1999;896:497-500.

20. Gornick ME. Disparities in Medicare services: potential causes, plausible explanations, and recommendations. Health Care Financ Rev. 2000;21(4):23-43.

21. Gornick ME, Egers PW, Reilly TW, et al. Effects of race and income on mortality and use of services among Medicare beneficiaries. N Engl J Med. 1996;335(11):791-99.

22. Wang J, Mullins CD, Chang CF, et al. Comparisons of changes over time in health expenditures per capita across racial and ethnic groups. Int J of Public Policy. 2010;6(3/4):172-89.

23. Gerber BS, Cho YI, Arozullah AM, Lee SY. Racial differences in medication adherence: a cross-sectional study of Medicare enrollees. Am J Geriatr Pharmacother. 2010;8(2):136-45.

24. Shi L, Green LH, Kazakova S. Primary care experience and racial disparities in self-reported health status. J Am Board Fam Pract. 2004;17(6):443-52.

25. Ciol MA, Shumway-Cook A, Hoffman JM, Yorkston KM, Dudgeon BJ, Chan L. Minority disparities in disability between Medicare beneficiaries. J Am Geriatr Soc. 2008;56(3):444-53.

26. Liberman JN, Roebuck MC. Prescription drug costs and generic dispensing ratio. J Manag Care Pharm. 2010;16(7):502-06. Available at: http://www. amcp.org/data/jmcp/502-506.pdf.

27. Buis M. Stata tip 87: interpretation of interactions in non-linear models. Available at: http://www.maartenbuis.nl/publications/interactions.pdf. Accessed September 19, 2015.

28. Chernew ME, Shah MR, Wegh A, et al. Impact of decreasing copayments on medication adherence within a disease management environment. Health Aff (Millwood). 2008;27(1):103-12.

29. Bautista RE, Rundle-Gonzalez V. Effects of antiepileptic drug characteristics on medication adherence. Epilepsy Behav. 2012;23(4):437-41.

30. Andersen RM. Revisiting the behavioral model and access to medical care: does it matter? J Health Soc Behav. 1995;36(1):1-10.

31. Iezzoni L, ed. Risk Adjustment for Measuring Healthcare Outcomes. 2nd ed. Chicago, IL: Health Administration Press; 1997.

32. Centers for Medicare \& Medicaid Services. Risk adjustment. Available at: http://www.cms.gov/Medicare/Health-Plans/MedicareAdvtgSpecRateStats/ Risk-Adjustors.html. Accessed September 19, 2015.

33. Koh HK, Graham G, Glied SA. Reducing racial and ethnic disparities: the action plan from the department of health and human services. Health Aff (Millwood). 2011;30(10):1822-29.

34. Weinick RM, Hasnain-Wynia R. Quality improvement efforts under health reform: how to ensure that they help reduce disparities-not increase them. Health Aff (Millwood). 2011;30(10):1837-43. 
Potential Health Implications of Medication Therapy Management Eligibility Criteria

in the Patient Protection and Affordable Care Act Across Racial and Ethnic Groups

35. Stuart B, Loh E, Miller L, Roberto P. Should eligibility for medication therapy management be based on drug adherence? J Manag Care Pharm. 2014;20(1):66-75. Available at: http://www.amcp.org/JMCP/2014/ January/17497/1033.html.

36. Stuart B, Loh FE, Roberto P, Miller LM. Increasing Medicare part D enrollment in medication therapy management could improve health and lower costs. Health Aff (Millwood). 2013;32(7):1212-20.
37. Medicare program; contract year 2015 policy and technical changes to the Medicare Advantage and the Medicare prescription drug benefit programs. 42 CFR 409, 417, 422, 423, 424 (2014). Available at: http://www.gpo.gov/ fdsys/pkg/FR-2014-01-10/pdf/2013-31497.pdf. Accessed September 21, 2015. 